\title{
The FORGE AHEAD clinical readiness consultation tool: a validated tool to assess clinical readiness for chronic disease care mobilization in Canada's First Nations
}

Mariam Naqshbandi Hayward ${ }^{1 *}$, Selam Mequanint ${ }^{1}$, Jann Paquette-Warren ${ }^{1}$, Ross Bailie ${ }^{2}$, Alexandra Chirila ${ }^{1}$, Roland Dyck ${ }^{3}$, Michael Green ${ }^{4}$, Anthony Hanley ${ }^{5}$, Jordan Tompkins', Stewart Harris ${ }^{1}$ and On behalf of the FORGE AHEAD Program Team

\begin{abstract}
Background: Given the astounding rates of diabetes and related complications, and the barriers to providing care present in Indigenous communities in Canada, intervention strategies that take into account contextual factors such as readiness to mobilize are needed to maximize improvements and increase the likelihood of success and sustainment. As part of the national FORGE AHEAD Program, we sought to develop, test and validate a clinical readiness consultation tool aimed at assessing the readiness of clinical teams working on-reserve in First Nations communities to participate in quality improvement (QI) to enhance diabetes care in Canada.

Methods: A literature review was conducted to identify existing readiness tools. The ABCD - SAT was adapted using a consensus approach that emphasized a community-based participatory approach and prioritized the knowledge and wisdom held by community members. The tool was piloted with a group of 16 people from 7 provinces and 11 partnering communities to assess language use, clarity, relevance, format, and ease of completion using examples. Internal reliability analysis and convergence validity were conducted with data from 53 clinical team members from 11 First Nations communities (3-5 per community) who have participated in the FORGE AHEAD program.

Results: The 27-page Clinical Readiness Consultation Tool (CRCT) consists of five main components, 21 sub-components, and 74 items that are aligned with the Expanded Chronic Care Model. Five-point Likert scale feedback from the pilot ranged from 3.25 to 4.5. Length of the tool was reported as a drawback but respondents noted that all the items were needed to provide a comprehensive picture of the healthcare system. Results for internal consistency showed that all sub-components except for two were within acceptable ranges (0.77-0.93). The Team Structure and Function sub-component scale had a moderately significant positive correlation with the validated Team Climate Inventory, $r=0.45, p<0.05$.

(Continued on next page)
\end{abstract}

\footnotetext{
* Correspondence: Mariam.Naqshbandi-Hayward@schulich.uwo.ca

${ }^{1}$ Centre for Studies in Family Medicine, Western Centre for Public Health and

Family Medicine, Department of Family Medicine, Schulich School of

Medicine and Dentistry, Western University, 1151 Richmond Street, London,

Ontario N6A 3K7, Canada

Full list of author information is available at the end of the article
}

(c) The Author(s). 2017 Open Access This article is distributed under the terms of the Creative Commons Attribution 4.0 International License (http://creativecommons.org/licenses/by/4.0/), which permits unrestricted use, distribution, and reproduction in any medium, provided you give appropriate credit to the original author(s) and the source, provide a link to the Creative Commons license, and indicate if changes were made. The Creative Commons Public Domain Dedication waiver (http://creativecommons.org/publicdomain/zero/1.0/) applies to the data made available in this article, unless otherwise stated. 
(Continued from previous page)

Conclusions: The testing and validation of the FORGE AHEAD CRCT demonstrated that the tool is acceptable, valid and reliable. The CRCT has been successfully used to support the implementation of the FORGE AHEAD Program and the health services changes that partnering First Nations communities have designed and undertaken to improve diabetes care.

Trial registration number: Current ClinicalTrial.gov protocol ID NCT02234973. Date of Registration: July 30, 2014

Keywords: Readiness, Diabetes mellitus, Quality improvement, Chronic disease, Indigenous, First Nations

\section{Background}

The burden of diabetes on both families and the healthcare system in Canada is growing at an astonishing pace with prevalence rates that have more than doubled in the last decade [1]. In 2010, 7.6\% of the total population had diabetes [2]. More alarming are the widening health disparities for Indigenous peoples in Canada [3]. With rising diabetes incidence and prevalence rates [1], higher rates of gestational diabetes [4], a younger age of diabetes diagnosis [5], increasing rates of type 2 diabetes in children and adolescents [6], and higher rates of diabetes complications and comorbidities [7], Indigenous population-specific interventions for type 2 diabetes have become vital. Such health disparities between Indigenous and non-Indigenous peoples have been observed in many countries around the world, primarily in relation to chronic diseases $[8,9]$. Consequently, more effective delivery of healthcare to Indigenous peoples has become an urgent priority.

It has been suggested that barriers to optimal diabetes care are different and sometimes more pronounced in Indigenous communities in Canada than those experienced in non-Indigenous communities due to geographic isolation, cultural differences and the disjointed healthcare provided by a combination of federal government, provinces and territories [10,11]. Given the barriers present in Indigenous communities such as availability and accessibility of primary healthcare services and professionals, appropriate and effective intervention strategies that take into account contextual factors in their planning and evaluation are needed to maximize improvements and increase the likelihood of success and sustainment $[12,13]$. Readiness is a measure of the recognition, preparation, and/or action taken when facing an area that requires change or improvement [14] and has been identified as a critical contextual factor to incorporate into public health interventions in Indigenous communities $[12,15]$.

When evaluating readiness relative to the healthcare setting in Indigenous communities in Canada, a valuable assessment is possible when all individuals involved in the prevention and treatment process participate (patients, the community, healthcare providers, etc.). The results of these evaluations can be used to guide care and maximize health improvements [16]. Holt et al [17] identified psychological and structural factors as key elements of health teams' readiness. Psychological factors are the beliefs an individual holds regarding change, recognition of the problem requiring change as a priority, and agreement with the change plans. Structural factors are the circumstances under which the change is being implemented such as an organization's capabilities and resources [17]. In an extensive review of 106 peer-reviewed articles on organizational readiness for change, Weiner et al [18] concluded that the content of a comprehensive organizational readiness tool should include a psychological and structural approach at an individual and organizational level that respects both macro-level structural factors and micro-level factors (e.g., individual differences). Recently, Attieh et al's [19] review of organizational readiness for knowledge translation in chronic care identified five core concepts, namely: organizational dynamics, change process, innovation readiness, institutional readiness and personal readiness.

Determination of health teams' degree of readiness is advantageous with regards to maximizing the success of interventions through the identification of available resources and the present knowledge of a health issue [20]. A low readiness score, for example, may indicate that healthcare staff face substantial challenges due to inadequate support from local staff, leadership or resources when implementing an intervention or program. In such an instance, an intervention should aim to address some of these challenges in order to increase the likelihood of success. By contrast, local staff can mount more complex interventions when a high degree of readiness is accessed owing to higher levels of leadership, resources and local knowledge or expertise.

The TransFORmation of IndiGEnous PrimAry HEAlthcare Delivery (FORGE AHEAD): Community-driven Innovations and Strategic Scale-up Toolkits is a 5-year national research program that partners with Indigenous communities in Canada to improve chronic disease care and access to available resources by developing and evaluating community-driven, culturally-relevant primary healthcare models through a quality improvement (QI) process [21]. The program uses a participatory research approach that simultaneously ensures culturally appropriate implementation and integrates knowledge 
translation by involving relevant stakeholders throughout the entire program. Two QI teams, a community and a clinical team, mobilized in each partnering community are provided training and support to implement various QI initiatives. Recognizing the importance of matching QI to a clinical teams' readiness level as essential for success and sustainment [17, 22]; and given the national scope of the FORGE AHEAD Program, a cost-effective and flexible clinical readiness consultation tool capable of identifying key factors that influence the adoption of initiatives to address chronic disease care in the unique communities in Canada was sought. We report here the development, testing and validation of the FORGE AHEAD CRCT.

\section{Methods}

\section{Aim, design and setting}

The objective was to develop a validated Clinical Readiness Consultation Tool (CRCT) to assess the readiness of clinical teams working on-reserve in Indigenous communities before they engage in QI efforts to enhance diabetes care in Canada. A consensus approach [23] within the community-based participatory research framework was utilized to develop and test the CRCT. Community-based participatory research emphasizes the recognition of a community as an equal partner and stakeholder that collaborates in all phases of the research [24]. Actions and decisions are made in a co-learning and knowledge sharing domain that facilitates research built on community strengths and adapts to community priorities to maximize both researcher and community benefits [24, 25]. The emergence of a co-operative model for health research and practice based on consensus with community partners is not new. The idea of working with communities rather than on communities is consistently recognized as a critical factor in research with Indigenous partners [23, 24, 26, 27]. The consensus approach based on the community-based participatory research framework differs from traditional approaches such as the Delphi process where emphasis is placed on expert knowledge and advanced detailed planning. Such traditional approaches have been documented as inappropriate when conducting health research with Indigenous community partners [24].

FORGE AHEAD partners with 11 First Nations communities across 6 provinces $(\mathrm{BC}, \mathrm{AB}, \mathrm{MB}, \mathrm{ON}, \mathrm{QC}, \mathrm{NL})$ and three isolation levels (isolated, non-isolated, and remote-isolated/semi-isolated).

\section{Development of the Clinical Readiness Consultation Tool (CRCT)}

A literature review was conducted in March 2014 using PubMed to identify existing clinical readiness tools published prior to January 2014. Key search terms included "Indigenous" or "First Nations" or "Aboriginal AND "healthcare" or "primary healthcare" or "chronic disease"
AND "clinical readiness", or "clinical change readiness" or "organizational readiness" or "organizational change" or "change management". With no tools found in the Canadian Indigenous domain, the search was expanded internationally, included all populations, and examined grey literature for key content. A total of 13 PubMed articles and four grey literature articles/sources were found. Inclusion criteria included use in Indigenous populations, a health domain tool, and restricted to clinicians (versus patients).

Members of the Working Group which consisted of experts in the fields of readiness, Indigenous research, survey development and chronic disease care/epidemiology assessed the literature to identify the most appropriate tools for use within FORGE AHEAD. From the review of literature, the Chronic Care Model [28], Expanded Chronic Care Model [29], Assessment of Chronic Illness Care (ACIC) tool [30] and the Audit and Best Practice for Chronic Disease - Systems Assessment Tool (ABCDSAT) $[31,32]$ were identified as key tools that examined organizations for strengths and areas to target for improvements or degree of readiness. The Chronic Care Model and the more health-promotion focused Expanded Chronic Care Model are both conceptual frameworks that guide implementation of chronic care, but cannot be used as practical tools to assess healthcare team readiness to address chronic disease change [33]. The ACIC and the ABCD-SAT, adapted from the ACIC to fit the local Australian setting, were both based on the concepts of the Chronic Care Model and emphasize systemlevel factors in the health setting for chronic disease change. Compared with the original ACIC scale, the adapted ABCD-SAT included three additional items (i.e., cultural competence, pathology management, and pharmacy management) [32]. The ABCD-SAT has been used extensively in Indigenous communities and health services in Australia, was designed to understand the state of development of health centre systems and inform decisions regarding priority areas for system improvement [32]. The ABCD-SAT is administered to a group of healthcare providers (managers, nurses, physicians) by external researchers or an external facilitator who guides the group through the components in the tool. The facilitator has been recognized as an integral part of using the ABCDSAT with clinics who have demonstrated a level of engagement, interest and commitment to quality improvement.

The aforementioned existing tools (Chronic Care Model, Expanded Chronic Care Model, ACIC, and ABCD-SAT) were considered for the FORGE AHEAD program; however the following drawbacks were identified: i) reliance on costly resources external to the community for tool implementation and/or interpretation, ii) not tailored to the unique Canadian setting and First Nations primary healthcare setting, iii) not focused on type 2 diabetes, iv) lack of a 
qualitative component where Indigenous team members' can add information regarding their insights and perceptions regarding diabetes care, and, v) no built-in mechanism to integrate individual perceptions to be used to support clinical readiness at a small group level. Therefore, the FORGE AHEAD Program aimed to develop and test a CRCT relevant to diabetes care in the Canadian Indigenous context that could be applied by primarily using existing internal community resources without the need for external interviewers and transcription. The ABCD-SAT (Version 2) was selected by the Working Group as the basis for conceptualizing and developing the CRCT. The overall goal of the Working Group was to develop a comprehensive, userfriendly, understandable, and stand-alone questionnaire that could be administered and used by community-based facilitators (rather than external interviewers) in First Nations communities within the FORGE AHEAD Program to assess readiness to adopt chronic disease interventions.

Adapting the ABCD-SAT into the CRCT involved a thorough review by Working Group members over a series of six rounds from January to July 2014. Each of the components and sub-components as well as the individual items that encompass the sub-components of the $\mathrm{ABCD}$ SAT were reviewed for relevance to the context of Canadian First Nations primary healthcare delivery systems, redundancies, cultural relevance, and language. One item was added on cultural competence and two questions about registries were removed. Type 2 diabetes specific examples were inserted to enhance clarity in most items. All items were revised to reflect the Canadian First Nations context and the language was adjusted for improved clarity and ease of understanding.

\section{Pilot testing}

In June 2014, 15 people from 7 provinces comprised of 3 co-investigators and 12 Indigenous and non-Indigenous community members from 11 partnering communities received the pilot CRCT. This group was selected given their prior involvement in the planning and development of the FORGE AHEAD Research Program proposal. Community members included family physicians, nurses, health managers and administrators, health promoters, and adult educators. The draft CRCT was distributed electronically along with a feedback form (see Additional file 1) that was designed to gather information on a five-point Likert scale on how respondents perceived the following: (1) appropriate language use for First Nations health clinics in Canada, (2) clarity of questions, (3) relevance of questions to health clinics in First Nations communities, (4) appropriate format for the tool, and, (5) helpfulness of examples provided for each question to complete the clinical assessment tool. A qualitative (open-ended questions) section asked respondents for suggestions, comments and specific recommendations. Respondents were asked to complete the questionnaire and insert comments in the questionnaire, as well as fill in the feedback form. To summarize the data, scores were tallied for each of the five scored domains and short responses and suggestions for improvements were summarized. All feedback received was incorporated into the revisions. The CRCT was deemed acceptable in each domain if a score of 3 or higher was received and if qualitative feedback did not raise concerns.

\section{Statistical validation of the tool}

To evaluate the technical quality of the CRCT, internal reliability analysis and convergence validity were conducted. Individuals involved in patient care from each of the FORGE AHEAD partnering communities were asked to complete the CRCT as part of the program intervention. A total of 53 clinical team members from 11 First Nations communities (3-5 FORGE AHEAD program participants per community) completed the CRCT at three time points: pre, during, and post program implementation. For this study, only pre-program implementation data was used to avoid a learning effect bias.

The internal reliability assessment was based on the correlations between the individual items that make up the sub-components, relative to the variances [34]. The internal consistency of each sub-component was calculated using Cronbach's alpha $(\alpha)$ which measures whether a group of items is related to a single construct or sub-component [35]. The higher the average correlation among the items, the higher the $\alpha$ but an $\alpha$ greater than 0.9 may also be indicative of a redundant item. An $\alpha$ greater than or equal to 0.7 is considered satisfactory (34). Sub-components with a single item were excluded from the internal consistency analysis. Overall $\alpha$ for the total scale (CRCT) was not calculated because each sub-component is intended to measure a distinct factor. Missing data was handled through pairwise deletion (available-case analysis) of cases. Descriptive statistics were generated to evaluate the score distribution and proportion of missing data per item. Items with high levels of missing data $(>10 \%)$ were identified and considered for further analysis and interpretation.

As part of FORGE AHEAD, participants also completed the Team Climate Inventory (TCI) to examine team functioning of clinical teams working on-reserve. The TCI (19 items divided into four subscales with either a 5 or 7 pointLikert scale) has been validated [36] and used in a variety of contexts [37]. The CRCT includes a sub-component that measures Team Structure and Function (TSF) with five 12 point-Likert scale items. Convergence validity analysis was carried out assessing the correlation between the scores of the TCI and TSF to evaluate the degree to which these tests assess the same construct [38]. Data was used in this analysis only when both tools were completed by the same individual during the same time period (pre-program 
implementation). The total score for each individual scale was calculated for each participant who completed both questionnaires. Pearson correlation, appropriate for interval scale data [39] was used to assess convergence validity. Statistical Analysis Software (SAS) version 9.2 was used to conduct the validation analysis.

\section{Results}

\section{FORGE AHEAD Clinical Readiness Consultation Tool (CRCT)}

The 27-page CRCT (see Additional file 2) has 4 main sections: 1) 1-page introduction describing the background, confidentiality, benefits, risks, reimbursement, consent, and contact information; 2) 1-page brief instruction (estimated time to complete, brief description of rating scales and how to submit the completed questionnaire); 3) general information (brief 8-item demographic profile); and 4) 5 main components and sub-components of healthcare systems important in chronic disease care (aligned with Expanded Chronic Care Model). The questionnaire is designed to be anonymous and provides a section to insert participant numbers.

A total of 74 items comprise the CRCT. Data on the general demographic characteristics of respondents were collected using the first 8 items. The rest of the items are categorized into 5 major components and a total of 21 sub-components (Table 1). The 5 components include Delivery System Design, Information Systems and Decision Support, Self-management Support, Linkages with Community Resources and Other Health Services, and Local Health Center Organizational Influence and Integration. Each sub-component consists of between 1 and 6 items and often includes an example. Items were rated on a four category 12-point Likert scale defined as 'limited or no support' (score 0-2), 'basic support' (score 3-5), 'good support' (score 6-8), and 'fully developed support' (score 9-11). For each category, brief descriptions guide participants to consider the score that best represents their clinical context. A justification box was provided below each item/rating scale for participants to explain their rating of provided written comments. Responses by each clinical team participant are calculated and summarized in an aggregated group report.

\section{Pilot testing results}

A total of 8 respondents from 4 provinces (2 CoInvestigators, 6 community representatives from 6 First $\mathrm{Na}$ tions communities) completed the feedback form for an overall review and response rate of $53.3 \%$. The CRCT took an average of $118 \mathrm{~min}$ to complete and ranged from 53 to $240 \mathrm{~min}$. Based on the five-point Likert scale feedback form, average respondent scores were: appropriate language use for First Nations health clinics in Canada (3.75); questions clearly written (3.25); questions are relevant to health
Table 1 Clinical Readiness Consultation Tool (CRCT) structure

\begin{tabular}{|c|c|}
\hline $\begin{array}{l}\text { Clinical Readiness Consultations: Components and } \\
\text { Sub-components }\end{array}$ & \# Items \\
\hline \multicolumn{2}{|l|}{ Component 1: Delivery System Design (28 items) } \\
\hline 1.1 Team Structure and Function & 5 \\
\hline 1.2 Clinical Leadership & 3 \\
\hline 1.3 Appointments and Scheduling & 3 \\
\hline 1.4 Care Planning & 2 \\
\hline 1.5 Systematic Approach to Follow-up & 4 \\
\hline 1.6 Continuity of Care & 2 \\
\hline 1.7 Patient Access & 2 \\
\hline 1.8 Cultural Competence/Knowledge & 4 \\
\hline 1.9 Physical Infrastructure & 3 \\
\hline \multicolumn{2}{|l|}{$\begin{array}{l}\text { Component 2: Information Systems and Decision } \\
\text { Support ( } 6 \text { items) }\end{array}$} \\
\hline $\begin{array}{l}\text { 2.1 Maintenance and Use of an Electronic or Paper } \\
\text { Diabetes Registry }\end{array}$ & 2 \\
\hline 2.2 Evidence-based Guidelines for Diabetes & 3 \\
\hline 2.3 Specialist and Generalist Collaboration & 1 \\
\hline \multicolumn{2}{|l|}{ Component 3: Self-management Support (7 items) } \\
\hline $\begin{array}{l}\text { 3.1 Self-Management Support, Assessment and } \\
\text { Documentation }\end{array}$ & 3 \\
\hline $\begin{array}{l}\text { 3.2 Self-management Education, Behavioral Risk } \\
\text { Reduction and Peer Support }\end{array}$ & 3 \\
\hline \multicolumn{2}{|l|}{$\begin{array}{l}\text { Component 4: Linkages with Community Resources } \\
\text { and Other Health Services ( } 15 \text { items) }\end{array}$} \\
\hline $\begin{array}{l}\text { 4.1 Communication and Cooperation of the Health } \\
\text { Center and Other Community-based Organizations } \\
\text { and Programs }\end{array}$ & 6 \\
\hline $\begin{array}{l}\text { 4.2 Linking Health Center Patients to Community } \\
\text { Resources }\end{array}$ & 3 \\
\hline 4.3 Community Outreach & 3 \\
\hline $\begin{array}{l}\text { 4.4 Regional Health Planning and Development of } \\
\text { Health Resources }\end{array}$ & 3 \\
\hline \multicolumn{2}{|l|}{$\begin{array}{l}\text { Component 5: Local Health Center Organizational } \\
\text { Influence and Integration (10 items) }\end{array}$} \\
\hline 5.1 Organizational Commitment & 5 \\
\hline 5.2 Quality Improvement Strategies & 4 \\
\hline $\begin{array}{l}5.3 \text { Integration of Health System Components to } \\
\text { Achieve High Quality Care for Patients with } \\
\text { Diabetes }\end{array}$ & 1 \\
\hline
\end{tabular}

clinics in First Nations communities (4); format of the tool is appropriate (4.5); and, helpfulness of examples to complete the clinical readiness assessment (4). The 12point Likert scale of the CRCT was maintained based on the qualitative feedback. Analysis of the written answers to open-ended questions revealed that although the questionnaire was long, respondents found that all the questions were important and necessary to obtain a comprehensive understanding of the current services available in communities. Some respondents noted that the language was 
geared for higher education/reading and comprehension skills. Revisions to the tool were made following the pilot to improve clarity to address this concern.

\section{Statistical validation of the tool Participant demographics}

Of the 53 people who completed the CRCT, 87\% were female and 62\% were Indigenous (see Table 2 for more participant demographics).

\section{Missing data}

There was a high completion rate for most of the items with only 8 items from three components left unanswered by more than $10 \%$ of the participants (see Table 3). Given the relatively high number of items in the CRCT, this represented a small number of items with missing data. Table 3 further shows that the majority of participants scored items of the CRCT between 3 and 7 on the interquartile range scale, indicating that the scores are not clustered together toward the low or high end of the scale.

\section{Internal consistency}

Two sub-components, namely, Specialist and Generalist Collaboration, and Integration of Health System, were excluded from the internal consistency analysis due to an insufficient number of items (single item) to calculate subcomponent $\alpha$. Results show that all sub-components except for two were within acceptable ranges (0.77-0.93) (Table 4). Two sub-components (Appointment and Scheduling, and Patient Access) had low $(<0.7)$ internal consistency while seven sub-components had $\alpha$ of above 0.9 .

The CRCT items with $\alpha<0.7$, a low level of correlation $(<0.4)$, and where removal of the item did not affect the total $\alpha$ (i.e., items which did not contribute meaningfully to the sub-component) were assessed by the Working Group members based on the internal consistency results and the theoretical concepts to ensure acceptability of the level of consistency and validity. Of the 68 items, only one was found to increase the reliability of the tool if removed. The

Table 2 Demographic characteristics of participants

\begin{tabular}{lll}
\hline Variable & Characteristics & N (\%) \\
\hline Gender & Female & $46(87 \%)$ \\
Indigenous & Yes & $33(62 \%)$ \\
Role & Family Physician & $7(13 \%)$ \\
& Nurse Practitioners & $4(8 \%)$ \\
& Registered Nurse & $16(30 \%)$ \\
& Registered Dietician & $4(8 \%)$ \\
& Health Director/Program Managers & $4(8 \%)$ \\
& Other (Clinical Assistances, Health & $18(34 \%)$ \\
& Care Aid, Case Manager etc.) & \\
\hline
\end{tabular}

Appointment and Scheduling sub-component had three items and removing the third item (Is it routine practice for the diabetes community based activities and programs to be planned or scheduled ahead of time?) improved the internal consistency of the sub-component (from 0.66 to 0.69). The two-item Patient Access sub-component was retained given that information related to patients' barriers to access are an important aspect of chronic disease care. Two items in the Communication and Cooperation subcomponent were removed due to redundancy $(\alpha=0.91)$, (Is patient satisfaction with health center services systematically and routinely assessed?) and (Do community, social, education and other programs and organizations have a strong health orientation?).

\section{Convergent validity}

Thirty-five participants completed both scales. The TCI global score ranged from 12.8 to 24 while the TSF subcomponent score ranges from 1.6 to 10.2 . The TSF subcomponent scale had a moderately significant positive correlation with the TCI, $r=0.45, p<0.05$ (Fig. 1).

\section{Discussion}

It has been argued that complex health interventions need to be context-dependent to be most effective [12, 23, 40]. Within the context of Indigenous communities in Canada where the barriers encountered to providing optimal chronic care are numerous, sometimes unique and typically more exacerbated compared to their non-Indigenous counterparts, and resources are scarce [23, 40-42] the wisdom held by healthcare providers working in a community with regards to implementation of an intervention should not be underestimated. The concept of readiness has been consistently argued to be a key factor in influencing the success of health interventions [17, 18, 30, 33]. Trickett [43] argues that political, financial, educational, cultural, logistic, anthropological, and emotional barriers can affect even strongly supported interventions within a health system. The Canadian Indigenous context and the healthcare models that exist in First Nations communities became an important underpinning for the development of the FORGE AHEAD CRCT. The CRCT has been utilized within the FORGE AHEAD Program to assess readiness of healthcare teams providing type 2 diabetes care to Indigenous communities across the country. Furthermore, the CRCT is used within the program as the foundation to begin engagement and consultation discussions among healthcare team members who bring diverse backgrounds and perspectives with regards to the development of QI initiatives to enhance diabetes care in their communities.

According to Holt et al. [44] and Weiner et al. [18], researchers need to give greater attention to the development, testing, and refining of organizational readiness for change tools. The FORGE AHEAD CRCT was developed 
Table 3 Descriptive statistics by CRCT item

\begin{tabular}{|c|c|c|c|c|c|c|}
\hline Sub-components & Items & $\mathrm{N}$ & Miss N (\%) & Median (IQR) ${ }^{\mathrm{a}}$ & $\operatorname{Min} N^{b}(\%)$ & $\operatorname{Max} N^{c}(\%$ \\
\hline \multirow[t]{5}{*}{ Team structure and function } & TeamFunction_1_1A & 52 & $1(1.9)$ & $8(3.5)$ & $1(1.9)$ & $5(9.6)$ \\
\hline & TeamFunction_1_1B & 53 & $\mathrm{O}(0.0)$ & $5(6)$ & $2(3.8)$ & $2(3.8)$ \\
\hline & TeamFunction_1_1C & 51 & $2(3.8)$ & $6(6)$ & 2(3.9) & 2(3.9) \\
\hline & TeamFunction_1_1D & 51 & $2(3.8)$ & $5(5)$ & $1(2.0)$ & 2(3.9) \\
\hline & TeamFunction_1_1E & 52 & $1(1.9)$ & $7.5(4)$ & $1(1.9)$ & $4(7.7)$ \\
\hline \multirow[t]{3}{*}{ Clinical leadership } & Leadership_1_2A & 53 & $0(0.0)$ & $8(5)$ & $1(1.9)$ & $5(9.4)$ \\
\hline & Leadership_1_2B & 50 & $3(5.7)$ & $8(4)$ & $1(2.0)$ & $4(8.0)$ \\
\hline & Leadership_1_2C & 50 & $3(5.7)$ & $7(4)$ & $3(6.0)$ & $3(6.0)$ \\
\hline \multirow[t]{3}{*}{ Appointments and scheduling } & Appointments_1_3A & 52 & $1(1.9)$ & $7(5)$ & $1(1.9)$ & $12(23.1)$ \\
\hline & Appointments_1_3B & 52 & $1(1.9)$ & $8(3)$ & $1(1.9)$ & $7(13.5)$ \\
\hline & Appointments_1_3C & 51 & $2(3.8)$ & $8(5)$ & $2(3.9)$ & 11(21.6) \\
\hline \multirow[t]{2}{*}{ Care planning } & CarePlanning_1_4A & 51 & 2(3.8) & $6(5)$ & $3(5.9)$ & $1(2.0)$ \\
\hline & CarePlanning_1_4B & 51 & $2(3.8)$ & $6(5)$ & $2(3.9)$ & $4(7.8)$ \\
\hline \multirow[t]{4}{*}{ Systematic approach to follow-up } & Followup_1_5A & 53 & $0(0.0)$ & $6(4)$ & 2(3.8) & $5(9.4)$ \\
\hline & Followup_1_5B & 51 & $2(3.8)$ & $9(5)$ & 2(3.9) & $9(17.7)$ \\
\hline & Followup_1_5C & 52 & $1(1.9)$ & $8.5(4)$ & $1(1.9)$ & $11(21.2)$ \\
\hline & Followup_1_5D & 52 & $1(1.9)$ & $5(8)$ & $13(25)$ & $4(7.7)$ \\
\hline \multirow[t]{2}{*}{ Continuity of care } & Continuity_1_6A & 52 & $1(1.9)$ & $6(4.5)$ & $5(9.6)$ & $5(9.6)$ \\
\hline & Continuity_1_6B & 51 & $2(3.8)$ & $7(5)$ & $1(2.0)$ & $3(5.9)$ \\
\hline \multirow[t]{2}{*}{ Patient access } & Access_1_7A & 51 & $2(3.8)$ & $8.5(4)$ & $1(2.0)$ & $9(17.3)$ \\
\hline & Access_1_7B & 49 & $4(7.5)$ & $9(5)$ & $2(4.1)$ & $13(26.5)$ \\
\hline \multirow[t]{4}{*}{ Cultural competence/Knowledge } & CulturalCompetence_1_8A & 51 & $2(3.8)$ & $8(5)$ & $2(3.9)$ & $6(11.8)$ \\
\hline & CulturalCompetence_1_8B & 46 & $7(13.2)$ & $9(3)$ & $3(6.5)$ & $14(30.4)$ \\
\hline & CulturalCompetence_1_8C & 50 & $3(5.7)$ & $6(5)$ & $3(6.0)$ & $7(14.0)$ \\
\hline & CulturalCompetence_1_8D & 51 & $2(3.8)$ & $9(5)$ & $1(2.0)$ & $13(25.5)$ \\
\hline \multirow[t]{3}{*}{ Physical infrastructure } & Infrastructure_1_9A & 53 & $0(0.0)$ & $8(5)$ & $1(1.9)$ & $11(20.8)$ \\
\hline & Infrastructure_1_9B & 51 & $2(3.8)$ & 10(3) & $1(2.0)$ & $21(41.2)$ \\
\hline & Infrastructure_1_9C & 52 & $1(1.9)$ & $8(5.5)$ & $1(2.0)$ & $13(25.0)$ \\
\hline \multirow[t]{2}{*}{ Diabetes registry } & Registry_2_1A & 48 & $5(9.4)$ & $6(6)$ & $5(10.4)$ & $7(14.6)$ \\
\hline & Registry_2_1B & 48 & $5(9.4)$ & $5(6)$ & $8(16.7)$ & $2(10.4)$ \\
\hline \multirow[t]{3}{*}{ Diabetes practice guidelines } & EBG_2_2A & 51 & $2(3.8)$ & $9(4)$ & $2(3.9)$ & $6(11.8)$ \\
\hline & EBG_2_2B & 51 & $2(3.8)$ & 9(3) & $3(5.9)$ & $8(15.7)$ \\
\hline & EBG_2_2C & 49 & $4(7.5)$ & $8(5)$ & $3(6.1)$ & $6(12.2)$ \\
\hline Specialist and generalist & Collaboration_2_3A & 51 & $2(3.8)$ & $8(6)$ & $3(5.9)$ & $5(9.8)$ \\
\hline \multirow[t]{3}{*}{ Self-management support } & SM_3_1A & 52 & $1(1.9)$ & $8(3)$ & $1(2.0)$ & $3(5.8)$ \\
\hline & SM_3_1B & 52 & $1(1.9)$ & $6(4.5)$ & $5(9.6)$ & 2(3.9) \\
\hline & SM_3_1C & 52 & $1(1.9)$ & $7(5)$ & 2(3.9) & $6(11.5)$ \\
\hline \multirow[t]{4}{*}{ Self-management education } & SM_3_2A & 49 & $4(7.5)$ & $8(4)$ & $2(4.1)$ & $6(12.2)$ \\
\hline & SM_3_2B & 49 & $4(7.5)$ & $5(6)$ & $3(6.1)$ & $5(10.2)$ \\
\hline & SM_3_2C & 52 & $1(1.9)$ & $6(4)$ & $4(7.7)$ & $4(7.7)$ \\
\hline & SM_3_2D & 53 & $0(0.0)$ & $8(3)$ & $2(3.8)$ & $5(9.4)$ \\
\hline \multirow[t]{3}{*}{ Communication and cooperation } & Communication_4_1A & 48 & $5(9.4)$ & $6.5(5)$ & $2(4.2)$ & $2(4.2)$ \\
\hline & Communication_4_1B & 49 & $4(7.5)$ & $7(5)$ & $1(2.0)$ & $4(8.2)$ \\
\hline & Communication_4_1C & 49 & $4(7.5)$ & $5(6)$ & $3(6.1)$ & $8(16.3)$ \\
\hline
\end{tabular}


Table 3 Descriptive statistics by CRCT item (Continued)

\begin{tabular}{|c|c|c|c|c|c|c|}
\hline & Communication_4_1D & 51 & $2(3.8)$ & $5(7)$ & $6(11.8)$ & 2(3.9) \\
\hline & Communication_4_1E & 48 & $5(9.4)$ & $8(4)$ & $3(6.3)$ & 2(4.2) \\
\hline & Communication_4_1F & 49 & $4(7.5)$ & $6(5)$ & $1(2.0)$ & $7(14.3)$ \\
\hline \multirow[t]{3}{*}{ Linking patients to community resources } & LinkResources_4_2A & 50 & $3(5.7)$ & $7.5(4)$ & $2(4.0)$ & $2(4.0)$ \\
\hline & LinkResources_4_2B & 47 & $6(11.3)$ & $5(7)$ & $5(10.7)$ & $1(2.1)$ \\
\hline & LinkResources_4_2C & 48 & $5(9.4)$ & $5(6)$ & $6(12.5)$ & $1(2.1)$ \\
\hline \multirow[t]{3}{*}{ Community outreach } & Outreach_4_3A & 51 & 2(3.8) & $9(4)$ & $1(2.0)$ & 10(19.6) \\
\hline & Outreach_4_3B & 47 & $6(11.3)$ & $7(4)$ & $2(4.3)$ & $3(6.4)$ \\
\hline & Outreach_4_3C & 50 & $3(5.7)$ & $7.5(4)$ & $1(2.0)$ & $3(6.0)$ \\
\hline \multirow[t]{3}{*}{ Planning and development } & Planning_4_4A & 42 & $11(20.8)$ & $5(6)$ & $5(11.9)$ & $5(11.9)$ \\
\hline & Planning_4_4B & 49 & $4(7.5)$ & $5(6)$ & $5(10.2)$ & $1(2.0)$ \\
\hline & Planning_4_4C & 43 & 10(18.9) & $5(6)$ & $6(14.0)$ & $4(9.3)$ \\
\hline \multirow[t]{5}{*}{ Organizational commitment } & OrgCommitment_5_1A & 48 & $5(9.4)$ & $8(4)$ & $1(2.1)$ & $3(6.3)$ \\
\hline & OrgCommitment_5_1B & 43 & 10(18.9) & $7(4)$ & $3(7.0)$ & $5(11.6)$ \\
\hline & OrgCommitment_5_1C & 50 & $3(5.7)$ & $6.5(4)$ & $1(2.0)$ & $5(10.0)$ \\
\hline & OrgCommitment_5_1D & 52 & $1(1.9)$ & $8(4)$ & $1(1.9)$ & $12(23.1)$ \\
\hline & OrgCommitment_5_1E & 50 & $3(5.7)$ & $8(5)$ & $1(2.0)$ & $8(16.0)$ \\
\hline \multirow[t]{4}{*}{ Quality improvement strategies } & QI_5_2A & 49 & $4(7.5)$ & 9(3) & $1(2.0)$ & $11(22.5)$ \\
\hline & QI_5_2B & 44 & $9(17.0)$ & $6.5(4)$ & $4(9.1)$ & 6(13.6) \\
\hline & QI_5_2C & 43 & 10(18.9) & $6(6)$ & $2(4.7)$ & $5(11.6)$ \\
\hline & QI_5_2D & 50 & $3(5.7)$ & $6(6)$ & $6(12.0)$ & $4(8.0)$ \\
\hline Integration of health system & Integration_5_3A & 52 & $1(1.9)$ & $6(4.5)$ & $2(3.9)$ & $4(7.7)$ \\
\hline
\end{tabular}

${ }^{a}$ IQR: Interquartile range calculated by subtracting the first quartile from the quartile of the data

${ }^{\mathrm{b}} \mathrm{Min} \mathrm{N}(\%)$ represents the number (percentage) of respondents ranked an item the minimum (0) in the CRCT scale

${ }^{c}$ Max $\mathrm{N}$ represents the number (percentage) of respondents ranked an item the maximum (12) in the CRCT scale

following a literature review that yielded the ABCD - SAT tool that was then adapted to the Canadian First Nations primary healthcare context using a consensus approach with thorough reviews and feedback from both First Nations community representatives and academic researchers. The CRCT pilot test results demonstrated good acceptability of the tool. Although length of the tool was noted as a drawback, all the questions were deemed important and necessary by respondents in understanding the current services available, and providing a comprehensive and complete picture of the existing healthcare delivery model in the community. Future work will aim to test the use of an on-line survey platform for communities with access to the internet. Such a platform may allow the information displayed to be customized for the respondent providing faster progression through the survey. Another possibility is having teams fill out the CRCT together rather than requesting individual team member completion first which could reduce the burden and focus teams together from the out-set. Concerns around the complexity of the language used were integrated into revisions following the pilot to simplify the language used in the tool.

Examination of the CRCT response data also demonstrated good acceptability of the tool with a high completion rate for all items except 8 that were left unanswered by more than $10 \%$ of the participants. Given the relatively high number of items in the CRCT, the proportion of unanswered items represents a small number. In addition, all items with higher proportions of missing data were those asking about the regional health planning and development, organizational commitment, or existing QI strategies at the health center. Given the fact that participants had a wide range of professional roles, this could be due to difficulty in understanding those questions and/or less knowledge about the issues that may have been more external to their role. In fact, of the four Health Directors/ Program Managers who completed the CRCT, all four answered all the questions about regional health planning and development, organizational commitment and existing QI strategies. Reliability analysis demonstrated an acceptable $\alpha$ score for the 19 sub-components (ranging from 0.77 to 0.93 ), which demonstrated adequate internal consistency for standard scale development criteria. Based on a rigorous review guided by theoretical and statistical principles, only three out of 74 items were removed.

As expected, the TSF sub-component of the FORGE AHEAD CRCT showed evidence of convergent validity when compared to the validated TCI tool. This suggests 
Table 4 Internal consistency of 21 sub-scales of the CRCT analysed per subcomponent

\begin{tabular}{|c|c|c|c|c|}
\hline Subcomponent & Items & Correlation with Total & Alpha(a) if deleted & $a$ \\
\hline \multirow[t]{5}{*}{ Team structure and function } & TeamFunction_1_1A & 0.77 & 0.91 & 0.92 \\
\hline & TeamFunction_1_1B & 0.85 & 0.89 & \\
\hline & TeamFunction_1_1C & 0.90 & 0.88 & \\
\hline & TeamFunction_1_1D & 0.74 & 0.91 & \\
\hline & TeamFunction_1_1E & 0.73 & 0.92 & \\
\hline \multirow[t]{3}{*}{ Clinical leadership } & Leadership_1_2A & 0.82 & 0.82 & 0.91 \\
\hline & Leadership_1_2B & 0.82 & 0.82 & \\
\hline & Leadership_1_2C & 0.83 & 0.83 & \\
\hline \multirow[t]{3}{*}{ Appointments and scheduling } & Appointments_1_3A & 0.53 & 0.49 & 0.66 \\
\hline & Appointments_1_3B & 0.52 & 0.52 & \\
\hline & Appointments_1_3C & 0.39 & 0.69 & \\
\hline \multirow[t]{2}{*}{ Care planning } & CarePlanning_1_4A & 0.80 & - & 0.89 \\
\hline & CarePlanning_1_4B & 0.80 & - & \\
\hline \multirow[t]{4}{*}{ Systematic approach to follow-up } & Followup_1_5A & 0.65 & 0.68 & 0.77 \\
\hline & Followup_1_5B & 0.61 & 0.69 & \\
\hline & Followup_1_5C & 0.63 & 0.68 & \\
\hline & Followup_1_5D & 0.45 & 0.80 & \\
\hline \multirow[t]{2}{*}{ Continuity of care } & Continuity_1_6A & 0.79 & - & 0.88 \\
\hline & Continuity_1_6B & 0.79 & - & \\
\hline \multirow[t]{2}{*}{ Patient access } & Access_1_7A & 0.47 & & 0.63 \\
\hline & Access_1_7B & 0.47 & & \\
\hline \multirow[t]{4}{*}{ Cultural competence/Knowledge } & CulturalCompetence_1_8A & 0.75 & 0.82 & 0.87 \\
\hline & CulturalCompetence_1_8B & 0.75 & 0.82 & \\
\hline & CulturalCompetence_1_8C & 0.76 & 0.82 & \\
\hline & CulturalCompetence_1_8D & 0.64 & 0.86 & \\
\hline \multirow[t]{3}{*}{ Physical infrastructure } & Infrastructure_1_9A & 0.59 & 0.64 & 0.74 \\
\hline & Infrastructure_1_9B & 0.50 & 0.73 & \\
\hline & Infrastructure_1_9C & 0.64 & 0.58 & \\
\hline \multirow[t]{2}{*}{ Diabetes registry } & Registry_2_1A & 0.84 & - & 0.91 \\
\hline & Registry_2_1B & 0.84 & - & \\
\hline \multirow[t]{3}{*}{ Diabetes practice guidelines } & EBG_2_2A & 0.83 & 0.72 & 0.85 \\
\hline & EBG_2_2B & 0.80 & 0.74 & \\
\hline & EBG_2_2C & 0.62 & 0.95 & \\
\hline \multirow[t]{3}{*}{ Self-management support } & SM_3_1A & 0.67 & 0.91 & 0.88 \\
\hline & SM_3_1B & 0.83 & 0.78 & \\
\hline & SM_3_1C & 0.83 & 0.77 & \\
\hline \multirow[t]{4}{*}{ Self-management education } & SM_3_2A & 0.77 & 0.88 & 0.90 \\
\hline & SM_3_2B & 0.81 & 0.87 & \\
\hline & SM_3_2C & 0.76 & 0.88 & \\
\hline & SM_3_2D & 0.81 & 0.87 & \\
\hline \multirow[t]{4}{*}{ Communication and cooperation } & Communication_4_1A & 0.84 & 0.88 & 0.91 \\
\hline & Communication_4_1B & 0.73 & 0.89 & \\
\hline & Communication_4_1C & 0.83 & 0.88 & \\
\hline & Communication_4_1D & 0.66 & 0.91 & \\
\hline
\end{tabular}


Table 4 Internal consistency of 21 sub-scales of the CRCT analysed per subcomponent (Continued)

\begin{tabular}{|c|c|c|c|c|}
\hline & Communication_4_1E & 0.83 & 0.88 & \\
\hline & Communication_4_1F & 0.61 & 0.91 & \\
\hline \multirow[t]{3}{*}{ Linking patients to community resources } & LinkResources_4_2A & 0.79 & 0.96 & \multirow[t]{3}{*}{0.93} \\
\hline & LinkResources_4_2B & 0.93 & 0.83 & \\
\hline & LinkResources_4_2C & 0.89 & 0.87 & \\
\hline \multirow[t]{3}{*}{ Community outreach } & Outreach_4_3A & 0.81 & 0.90 & \multirow[t]{3}{*}{0.92} \\
\hline & Outreach_4_3B & 0.82 & 0.88 & \\
\hline & Outreach_4_3C & 0.86 & 0.85 & \\
\hline \multirow[t]{3}{*}{ Planning and development } & Planning_4_4A & 0.78 & 0.74 & \multirow[t]{3}{*}{0.85} \\
\hline & Planning_4_4B & 0.69 & 0.83 & \\
\hline & Planning_4_4C & 0.71 & 0.81 & \\
\hline \multirow[t]{5}{*}{ Organizational commitment } & OrgCommitment_5_1A & 0.83 & 0.86 & \multirow[t]{5}{*}{0.90} \\
\hline & OrgCommitment_5_1B & 0.77 & 0.88 & \\
\hline & OrgCommitment_5_1C & 0.71 & 0.89 & \\
\hline & OrgCommitment_5_1D & 0.76 & 0.88 & \\
\hline & OrgCommitment_5_1E & 0.74 & 0.89 & \\
\hline \multirow[t]{4}{*}{ Quality improvement strategies } & QI_5_2A & 0.70 & 0.93 & \multirow[t]{4}{*}{0.92} \\
\hline & QI_5_2B & 0.82 & 0.89 & \\
\hline & Ql_5_2C & 0.90 & 0.86 & \\
\hline & Q1_5_2D & 0.84 & 0.88 & \\
\hline
\end{tabular}

that the sub-component of the CRCT intended to examine team functioning measures the same construct as the TCI. The moderate level of correlation is acceptable and can partly be explained by the fact that the TSF and TCI are structured differently with varying scales and types of questions. While the CRCT instrument has demonstrated validity and reliability, there are limitations. The small sample size did not allow for a confirmatory factory analysis to test whether the data collected from First Nations communities in Canada fits with the hypothesized measurement of readiness using the CRCT. Future confirmatory factor analysis studies with larger samples are suggested to better establish the validity of the FORGE AHEAD CRCT. Also, the

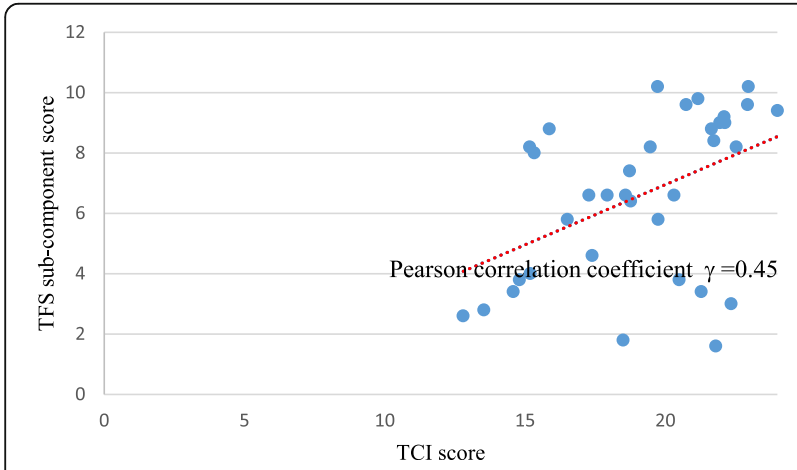

Fig. 1 Scatter plot showing the moderate correlation between $\mathrm{TCl}$ and TSF sub-components of the CRCT psychometric properties of convergent validity for the entire CRCT could not be evaluated due to the non-existence of validated tools that measure a similar concept. As such, only the TSF sub-component was tested for convergent validity against the validated TCI.

The FORGE AHEAD Program is still in its implementation phase and as such, complete data are not yet available on the recruitment and retention of partnering communities, community and clinical team members QI initiatives, clinical outcomes, and cost analyses. Data on the use of the CRCT to facilitate QI initiatives and the impact of the CRCT on health-related outcomes will be available upon completion of the program. Detailed process evaluations including stakeholder interviews will inform further revisions to the CRCT as well as best practices for the successful implementation and scale-up of the tool. Process evaluations will also highlight how the CRCT enabled understanding and relationship building among healthcare team members working in Indigenous communities and between researchers and community stakeholders.

\section{Conclusions}

In conclusion, the validated CRCT has been successfully used to support the implementation of the FORGE AHEAD Program and the health services changes that partnering First Nations communities have designed and undertaken to improve diabetes care. 


\section{Additional files}

Additional file 1: FORGE AHEAD: Clinical Readiness Consultation Tool Community Feedback Form. The Community Feedback Form was used during the pilot of the CRCT and was includes a qualitative (open-ended) section for suggestions/comments and a five-point Likert scale to gather responses on the following: (1) appropriate language use for First Nations health clinics in Canada, (2) clarity of questions, (3) relevance of questions to health clinics in First Nations communities, (4) appropriate format for the tool, and, (5) helpfulness of examples provided for each question to complete the clinical assessment tool. (DOCX $43 \mathrm{~kb}$ )

Additional file 2: FORGE AHEAD: Clinical Readiness Consultation Tool. The 27-page tool has 4 main sections: 1) 1-page introduction describing the background, confidentiality, benefits, risks, reimbursement, consent, and contact information; 2) 1-page brief instruction (estimated time to complete, brief description of rating scales and how to submit the completed questionnaire); 3) general information (brief 8-item demographic profile); and 4) 5 main components and sub-components of healthcare systems important in chronic disease care. (DOCX $92 \mathrm{~kb}$ )

\section{Abbreviations}

ABCD - SAT: Audit and Best Practice for Chronic Disease - Systems Assessment Tool; ACIC: Assessment of chronic illness care; CRCT: Clinical readiness consultation tool; FORGE AHEAD: Transformation of Indigenous Primary Healthcare Delivery; QI: Quality improvement; TCl: Team climate inventory; TSF: Team Structure and Function sub-component of the CRCT

\section{Acknowledgments}

On behalf of the FORGE AHEAD Program Team (see table below). This work was supported by the Canadian Institutes of Health Research (funding reference numbers \#MCO 117675, \#297910, and \#PME-133824). This work was generously supported by The Lawson Foundation. This research was conducted with the support of a grant from AstraZeneca Canada Inc. The authors acknowledge the editorial assistance of Marie Tyler, research assistant at the Centre for Studies in Family Medicine, Western University, London, Ontario, and the expert advice of Dr. David Dannenbaum at the Cree Board of Health \& Social Services of James Bay, Montreal, Quebec.

\section{Name}

\section{Principal investigator}

Stewart Harris, CM, MD, MPH, Western University, London, ON FCFP, FACPM

\section{Co-investigators}

Ed Barre, PhD

Onil Bhattacharyya, MD, PhD

David Dannenbaum, MD

Keith Dawson, MD, PhD

Roland Dyck, MD, FRCPC

Jo-Ann Episkenew, PhD

Michael Green, MD, MSc, FCFP

Anthony Hanley, PhD

Cape Breton University, Sydney, NS

Women's College Research Institute University of Toronto, Toronto, ON

Cree Board of Health \& Social Services of James Bay, Montreal, QC

University of British Columbia, Vancouver, BC

University of Saskatchewan, Saskatoon, SK

University of Saskatchewan, Regina, SK

Queen's University, Kingston, ON

University of Toronto, Toronto, ON

Barry Lavallee, MD, CCFP, FCFP, University of Manitoba, Winnipeg, MB MCISC

Ann Macaulay, CM, MD, FCFP, McGill University, Montreal, QC FRCPC (Hon)

(Continued)

Alex McComber, MEd

Monica Parry, RN, MEd,

MSc, PhD

Sonja Reichert, MD, MSc, CCFP

Jon Salsberg, MA, PHD (c.)

Amardeep Thind, MD, PhD

Sheldon Tobe, MD, MScCH (HPTE), FRCPC, FACP, FASH

Ellen Toth, MD

Audrey Walsh, RN, PhD

Jay Wortman, MD

Lloy Wylie, PhD

Merrick Zwarenstein, MBBCh, MSc, PhD

\section{Collaborators}

Ross Bailie, MD, PhD

Kayla Collins, PhD

Claire de Oliveira, MA, PhD

Michael Hindmarsh, BASC MA, PhD (ABD)

Valeria Rac, MD, PhD

Linda Stanley, BS, MS, PhD

\section{Policy maker \& knowledge user organizations}

Joanne Lewis

Marlene Nosé

Brigitte Parent

Stephen Sundquist

\section{Wave 1 - Partnering communities}

Lillian Houle

Amber Houle

Dawn Montour-Lazare

Joelle Emond

Jessica Jacobs

Randy Littlechild

Bonny Graham

Tina Littlechild
Kahnawake Mohawk Territory,

Montreal, QC

University of Toronto, Toronto, ON

Western University, London, ON

McGill University, Montreal, QC

Western University, London, ON

Sunnybrook Research Institute University of Toronto, Toronto, ON

University of Alberta, Edmonton, $A B$

Cape Breton University, Sydney, NS

University of British Columbia, Vancouver, BC

Western University, London, ON

Western University, London, ON

Menzies School of Health Research, Brisbane, QLD Australia

Newfoundland and Labrador Centre for Health Information

St. John's, NL

Centre for Addiction and Mental Health (CAMH) Institute of Health Policy, Management and Evaluation (IHPME), University of Toronto, ON

Hindsight Healthcare Strategies, Toronto, ON

Toronto Health Economics and Technology Assessment (THETA) Collaborative, University of Toronto, Toronto, ON

Tri-Ethnic Research Center, Colorado State University

Colorado, CO, USA

Canadian Diabetes Association, Toronto, ON

Health Canada, FNIHB, Ottawa, ON

Assembly of First Nations, Ottawa, ON

Ontario Stroke Network (also on behalf of the Heart \& Stroke Foundation), Toronto, ON

Ebb and Flow First Nation, Ebb and Flow, MB

Kahnawake Mohawk, Montreal, QC

Maskwacis Health, Hobbema, AB 


\section{(Continued)}

\begin{tabular}{ll}
\hline Devon Guy & Tsuu T'ina Nation, Calgary, AB \\
Chalsea Onespot & \\
Ivan Kimble McComb & Waskaganish First Nations, Eastern \\
Emilie Dufour & James Bay, QC \\
Verna Jolly & \\
Charlene Diamond &
\end{tabular}

\section{Wave 2 - Partnering communities}

Jennifer Jones

Danna Hadden

Cowichan Tribes, BC

April DeYaeger

Theresa O'Keefe

Ada Roberts

Maggie Organ

Shelley Kirkness

Marie Jebb

Carla Constant

Allen Deleary

Rennie Nawash

Lori Sinclair

Heather McDonald

Bonnie Nickel

\section{Western research staff}

Mariam Naqshbandi Hayward, $\mathrm{BA}, \mathrm{MSC}$

$\begin{array}{ll}\begin{array}{l}\text { Selam Mequanint, BSc, MTech } \\ \text { Jann Paquette-Warren, MSc }\end{array} & \text { Western University, London, ON } \\ \text { Jordan Tompkins, BSc, MA } & \text { Western University, London, ON } \\ \begin{array}{l}\text { Susan Webster-Bogaert, BSc } \\ \text { (KIN), MA }\end{array} & \text { Western University, London, ON } \\ \text { Braden Te Hiwi, MHK } & \text { Western University, London, ON } \\ \text { Harsh Zaran, MA, MGA } & \text { Western University, London, ON } \\ \text { Jim Esler, MA } & \text { Western University, London, ON } \\ \text { Meghan Fournie, BA } & \text { Western University, London, ON } \\ \text { Marie Tyler, MSc } & \text { Western University, London, ON } \\ \text { Jackie McLellan } & \text { Western University, London, ON } \\ \text { Marnie Orcutt } & \text { Western University, London, ON }\end{array}$

\section{Funding}

This work was supported by the Canadian Institutes of Health Research (funding reference numbers \#MCO 117675, \#297910, and \#PME-133824). This work was generously supported by The Lawson Foundation. This research was conducted with the support of a grant from AstraZeneca Canada Inc. No funding partners were involved in the design of the study, data collection, analysis, interpretation of the data or in writing the manuscript.

\section{Availability of data and materials}

The datasets generated during and/or analysed during the current study are not publicly available due to lack of permission from our partnering First Nations communities and individual participants but are available from the corresponding author on reasonable request and approval from partnering communities and individual participants.

\section{Authors' contributions}

MNH is the lead coordinator for the FORGE AHEAD Program, wrote all drafts of the manuscript, integrated all feedback upon reviews and finalized the manuscript. SM performed the statistical analyses for the manuscript and drafted the sections on the statistical analyses. JPW was also the lead coordinator of the FORGE AHEAD Program and was involved along with RB, $\mathrm{RD}, \mathrm{MG}, \mathrm{AH}$, and JT in the development of the Clinical Readiness Consultation Tool. AC completed the literature search and assisted in drafting sections of the manuscript. MNH, JPW and SH conceived the program along with the entire FORGE AHEAD Team and participated in its design as well as the development of all tools and strategies used within the program. SH is the Principal Investigator of the FORGE AHEAD Program. All authors (MNH, SM, JPW, $\mathrm{RB}, \mathrm{AC}, \mathrm{RD}, \mathrm{MG}, \mathrm{AH}, \mathrm{JT}$ and $\mathrm{SH}$ ) reviewed drafts of the manuscript, and read and approved the final manuscript.

\section{Authors' information}

Not applicable

\section{Competing interests}

MNH, SM, JPW, JT and SH were funded from the grant supporting this study. All remaining authors declare that they have no competing interests.

\section{Consent for publication}

Not applicable

\section{Ethics approval and consent to participate}

In line with the participatory nature of the development of the FORGE AHEAD CRCT, the program protocol was submitted for academic and community-based ethical reviews. Academic ethics approval was obtained from the Western University Health Science Research Ethics Board in London, Ontario (\#103895, approved June 17, 2013) and the Health Research Ethics Board of Alberta (CHC-14-0054, approved December 1, 2014). Communitybased ethics review approvals in Indigenous communities included: The Cree Board of Health and Social Services of James Bay (\#2014-DSP-03, approved October 2, 2014), Mi'kmaw Ethics Watch, Unama'ki College, Cape Breton University (approved January 29, 2014), and Mi'kmaq Confederacy Ethics Review Committee, Prince Edward Island (approved March 14, 2014). First Nations communities were recruited into the FORGE AHEAD program through self-expressed interest in response to regional and website sharing of program information and/or personal communication by investigators with pre-existing community partnerships. Community participation was confirmed by signed research and financial agreements with each community. Participants consist of a Community Team and a Clinical Team that are each comprised of three to five consenting community members. Signed informed consent was utilized for each team member.

\section{Publisher's Note}

Springer Nature remains neutral with regard to jurisdictional claims in published maps and institutional affiliations.

\section{Author details}

${ }^{1}$ Centre for Studies in Family Medicine, Western Centre for Public Health and Family Medicine, Department of Family Medicine, Schulich School of Medicine and Dentistry, Western University, 1151 Richmond Street, London, Ontario N6A 3K7, Canada. ${ }^{2}$ Menzies School of Health Research, Charles Darwin University, Darwin, Northern Territory, Australia. ${ }^{3}$ Canadian Center for Health and Safety in Agriculture, Department of Medicine, College of Medicine, University of Saskatchewan, Saskatoon, Saskatchewan, Canada. ${ }^{4}$ Departments of Family Medicine and Public Health Sciences, Queen's University, Kingston, Ontario, Canada. ${ }^{5}$ Departments of Nutritional Sciences and Medicine and the Dalla Lana School of Public Health, University of Toronto, Toronto, Ontario, Canada.

Received: 9 February 2016 Accepted: 18 March 2017

Published online: 23 March 2017

\section{References}

1. Canadian Diabetes Association. 2015 report on diabetes - driving change. Toronto: CDA; 2015. http://www.diabetes.ca/getmedia/5a7070fo-77ad-41ad9e95-ec1 bc56ebf85/2015-report-on-diabetes-driving-change-english.pdf. aspx. Accessed 8 Feb 2016

2. Public Health Agency of Canada. Canadian Chronic Disease Surveillance System 1999/2000-2010/2011. 2014. Available from: http://open.canada. ca/data/en/dataset/9525c8c0-554a-461b-a763-f1657acb9c9d. Accessed 10 Dec 2015. 
3. Harris SB, Gittelsohn J, Hanley A, Barnie A, Wolever TMS, Gao J, et al. The prevalence of NIDDM and associated risk factors in Native Canadians. Diabetes Care. 1997;20:185-7.

4. Dyck R, Klomp H, Tan LK, Turnell RW, Boctor MA. A comparison of rates, risk factors, and outcomes of gestational diabetes between aboriginal and nonaboriginal women in the Saskatoon health district. Diabetes Care. 2002;25: 487-93.

5. Oster RT, Johnson JA, Hemmelgarn BR, King M, Balko SU, Svenson LW, et al. Recent epidemiologic trends of diabetes mellitus among status Aboriginal adults. Can Med Assoc J. 2011; doi:10.1503/cmaj.10101882.

6. Dean HJ, Mundy RL, Moffatt M. Non-insulin-dependent diabetes mellitus in Indian children in Manitoba. CMAJ. 1992;147:52-7.

7. Harris SB, Naqshbandi M, Bhattacharyya O, Hanley AJ, Esler JG, Zinman B, et al. Major gaps in diabetes clinical care among Canada's First Nations: results of the CIRCLE study. Diabetes Res Clin Pract. 2011;92:272-9.

8. Mohindra KS. Research and the health of Indigenous populations in lowand middle-income countries. Health Promot Int. 2015; doi:10.1093/heapro/ day 106

9. Naqshbandi M, Harris SB, Esler JG, Antwi-Nsiah F. Global complication rates of type 2 diabetes in Indigenous peoples: a comprehensive review. Diabetes Res Clin Pract. 2008:82:1-17.

10. Bhattacharyya OK, Rasooly IR, Naqshbandi M, Estey EA, Esler J, Toth E, et al. Challenges to the provision of diabetes care in First Nations communities: results from a national survey of healthcare providers in Canada. BMC Health Serv Res. 2011; doi:10.1186/1472-6963-11-283.

11. Ministry Advisory Council on Rural Health. Rural health in rural hands: Strategic directions for rural, remote, northern and Aboriginal communities. Health Canada; 2002. http://ruralontarioinstitute.ca/file.aspx?id=29b5ba0bc6ce-489f-bb07-2febfb576daa. Accessed 8 Feb 2016.

12. Kostadinov I, Daniel M, Stanley L, Gancia A, Cargo M. A systematic review of community readiness tool applications: implications for reporting. Int J Environ Res Public Health. 2015;12:3453-68.

13. Michiel Oosterveer T, Kue Young T. Primary health care accessibility challenges in remote indigenous communities in Canada's North. Int Circumpolar Health. 2015; https://www.ncbi.nlm.nih.gov/pmc/articles/ PMC4623283/. Accessed 8 Feb 2016.

14. Oetting E, Plested B, Edwards R, Thurman P, Kelly K, Beauvais F. Community readiness for community change. 2014. Available from: http:// triethniccenter.colostate.edu/docs/CR_Handbook_8-3-15.pdf. Accessed 12 Nov 2015.

15. Montague TJ, Gogovor A, Krelenbaum M. Time for chronic disease care and management. Can J Cardiol. 2007;23:971-5.

16. Edwards RW, Jumper-Thurman P, Plested BA, Oetting ER, Swanson L. Community readiness: research to practice. J Community Psychol. 2000;28: 291-307.

17. Holt DT, Helfrich CD, Hall CG, Weiner BJ. Are you ready? How health professionals can comprehensively conceptualize readiness for change. J Gen Intern Med. 2010;25 Suppl 1:50-5.

18. Weiner BJ, Amick H, Lee SY. Conceptualization and measurement of organizational readiness for change: a review of the literature in health services research and other fields. Med Care Res Rev. 2008;65:379-436. MCRR.

19. Attieh R, Gagnon M-P, Estabrooks CA, Légaré F, Ouimet M, Roch G, et al. Organizational readiness for knowledge translation in chronic care: a review of theoretical components. Implement Sci. 2013;8:138.

20. Jarpe-Ratner E. Using the community readiness model as an approach to formative evaluation. Health Promot Pract. 2013:14:649-55.

21. The National Diabetes Management Strategy. FORGE AHEAD Program description. 2016. Available from: http://tndms.ca/forgeahead/index.html. Accessed 19 Jan 2016

22. Kelly KJ, Edwards RW, Comello MLG, Plested BA, Thurman PJ, Slater MD. The community readiness model: a complementary approach to social marketing. Mark Theory. 2003;3:411-26.

23. Maar M, Yeates K, Barron M, Hua D, Liu P, Lum-Kwong MM, et al. I-RREACH: an engagement and assessment tool for improving implementation readiness of researchers, organizations and communities in complex interventions. Implement Sci. 2015; doi: 10.1186/s13012-015-0257-6.

24. Macaulay AC, Harris SB, Lévesque L, Cargo M, Ford E, Salsberg J, et al. Primary prevention of type 2 diabetes: experiences of 2 aboriginal communities in Canada. Can J Diabetes. 2003:27:464-75.
25. Israel BA, Schulz AJ, Parker EA, Becker AB. Review of community-based research: assessing partnership approaches to improve public health. Annu Rev Public Health. 1998;19:173-202.

26. Ross MG, Lappin B. Community organization; theory, principles, and practice. 2dth ed. New York: Harper \& Row; 1967.

27. Rothman J. Planning and organizing for social change; action principles from social science research. New York: Columbia University Press; 1974.

28. Wagner EH, Austin BT, Davis C, Hindmarsh M, Schaefer J, Bonomi A. Improving chronic illness care: translating evidence into action. Health Aff Proj Hope. 2001;20:64-78.

29. Barr VJ, Robinson S, Marin-Link B, Underhill L, Dotts A, Ravensdale D, et al. The expanded Chronic Care Model: an integration of concepts and strategies from population health promotion and the Chronic Care Model. Hosp Q. 2003;7:73-82.

30. Bonomi AE, Wagner EH, Glasgow RE, VonKorff M. Assessment of chronic illness care (ACIC): a practical tool to measure quality improvement. Health Serv Res. 2002:37:791-820

31. Menzies School of Health Research. Systems Assessment Tool. 2013. Available from: http://www.one21seventy.org.au/cqi-information/systemsassessment-tool. Accessed 8 Feb 2016.

32. Si D, Bailie R, Connors C, Dowden M, Stewart A, Robinson G, et al. Assessing health centre systems for guiding improvement in diabetes care. BMC Health Serv Res. 2005;5:56.

33. Gagnon MP, Labarthe J, Legare F, Ouimet M, Estabrooks CA, Roch G, et al Measuring organizational readiness for knowledge translation in chronic care. Implement Sci. 2011; doi:10.1186/1748-5908-6-72.

34. Smit GJ. Psigometrika. Pretoria: HAUM-Tersiër; 1991.

35. Cronbach LJ. Coefficient alpha and the internal structure of tests. Psychometricka. 1951;16:297-334

36. Beaulieu MD, Dragieva N, Grande CD, Dawson J, Haggerty JL, Barnsley J, et al. The team climate inventory as a measure of primary care teams' processes: validation of the French version. Healthc Policy Polit Sante. 2014; 9:40-54.

37. Beaulieu M-D, Haggerty J, Tousignant P, Barnsley J, Hogg W, Geneau R, et al. Characteristics of primary care practices associated with high quality of care. CMAJ. 2013;185:E590-6.

38. Gregory RJ. Psychological testing: history, principles, and applications. 6th ed. Boston: Pearson; 2010.

39. Boone, Harry N. Jr, Boone DA. Analyzing Likert Data. J Ext. 2012. Available from: http://www.joe.org/joe/2012april/tt2.php. Accessed 8 Feb 2016.

40. Green LW. Caveats on coalitions: in praise of partnerships. Health Promot Pract. 2000;1:64-5.

41. King $M$, Smith A, Gracey $M$. Indigenous perspectives on health: The underlying causes of the health gap. Lancet. 2009;374:76-85.

42. Marrone S. Understanding barriers to health care: a review of disparities in health care services among indigenous populations. Int J Circumpolar Health. 2007:66:188-98.

43 Trickett EJ. Community-based participatory research as worldview or instrumental Strategy: Is it lost in translation(al) research? Am J Public Health. 2011;101:1353-5.

44 Holt DT, Achilles AA, Harris SG. Toward a comprehensive definition of readiness for change: a review of research and instrumentation. In: Research in organizational change and development. 2007. http://www. emeraldinsight.com/doi/pdfplus/10.1016/S0897-3016\%2806\%2916009-7. Accessed 4 Feb 2016

\section{Submit your next manuscript to BioMed Central and we will help you at every step:}

- We accept pre-submission inquiries

- Our selector tool helps you to find the most relevant journal

- We provide round the clock customer support

- Convenient online submission

- Thorough peer review

- Inclusion in PubMed and all major indexing services

- Maximum visibility for your research

Submit your manuscript at www.biomedcentral.com/submit 